\title{
Achievement Goals in Social Interactions: Learning with Mastery vs. Performance Goals
}

\author{
Céline Darnon • Fabrizio Butera • \\ Judith M. Harackiewicz
}

Published online: 4 January 2007

(C) Springer Science+Business Media, LLC 2006

\begin{abstract}
Little work has studied achievement goals in social interaction situations. The present experiment aimed at contributing to this matter by showing the potential of social interaction (in particular disagreement) to moderate the effects of achievement goals on learning. Participants were led to think they interacted with a partner, sharing opinions about a text that they were studying. Mastery and performance goals were manipulated. During the "interaction," they received either disagreement or agreement from this bogus partner. Results showed that a condition in which mastery goals were induced led to better learning than a performance goal condition only when the partner disagreed. No differences between goal conditions were observed when the
\end{abstract}

Part of this work was conducted during Céline Darnon's doctoral dissertation under the supervision of Fabrizio Butera, and was written during Céline Darnon's post-doctorate at the University of Wisconsin-Madison, USA, thanks to a Fulbright fellowship.

\section{Darnon}

Laboratoire de Psychologie Sociale de Grenoble-Chambéry, Université Pierre Mendès France,

Grenoble, France

J. M. Harackiewicz

Department of Psychology, University of Wisconsin-Madison, Madison, USA

F. Butera $(\square)$

Institut des Sciences Sociales et Pédagogiques, Université de Lausanne - Anthropole,

CH 1015 Lausanne, Suisse (Switzerland)

e-mail: fabrizio.butera@unil.ch

Present address:

C. Darnon

Laboratoire de Psychologie Sociale et Cognitive, Université

Blaise Pascal,

Clermont-Ferrand, France partner agreed. Implications for achievement goal research are discussed.

Keywords Mastery goals $\cdot$ Performance goals $\cdot$ Social interactions $\cdot$ Conflict $\cdot$ Learning

The achievement goals framework (e.g., Dweck, 1986; Nicholls, 1984) has produced an abundant body of literature on achievement-relevant behaviors (such as learning, interest in the task, persistence, reaction to failure). In this framework, two goals-mastery and performance goals-are distinguished. Mastery goals correspond to the desire to understand a task, acquire new knowledge, and develop abilities. Conversely, performance goals refer to the desire to show competencies by trying to obtain positive judgments. Recent research shows that these two goals can also be divided into approach and avoidance goals (Elliot, 1997). In this paper however, we will focus on the approach form of performance and mastery goals, which have been studied the most extensively and which have been the subject of most debate (cf. Harackiewicz, Barron, Pintrich, Elliot, \& Thrash, 2002; Midgley, Kaplan, \& Middleton, 2001). An extensive body of literature has described the features of these two goals and their effects on different achievement outcomes (for reviews, see Harackiewicz, Barron, \& Elliot, 1998; Dweck, 1986). For example, goals have been shown to influence the way a task is undertaken. Under mastery goals, attention is allocated to the resolution of the task: Researchers have shown that mastery goals favor a deep processing of the task (e.g., Nolen, 1988), while under performance goals, attention is shared between the task and concern about performance outcomes (Elliott \& Dweck, 1988), which results in a more superficial processing of the task (Nolen, 1988).

Although abundant, this literature nevertheless leaves two intertwined questions unanswered. The first is the lack of 
direct empirical evidence that learning (the ability to assimilate and generalize knowledge acquired after a lesson or after an exercise) is better when students pursue mastery goals than when they pursue performance goals. Indeed, for years, it has been argued that mastery goals should enhance learning and performance goals should impair it (see Dweck, 1986), and a few studies have demonstrated the expected positive link between mastery goals and learning (Covington \& Omelich, 1984; Elliot \& McGregor, 1999; Grant \& Dweck, 2003, Licht \& Dweck, 1984). However, many more studies failed to find positive mastery goal effects (e.g., Harackiewicz, Barron, Carter, Lehto, \& Elliot, 1997). Moreover, these same studies failed to observe the expected negative link between performance goals and learning (see Harackiewicz et al., 2002, for review). Thus, the first question concerns the conditions under which we should observe differences between mastery and performance goals.

The second question concerns the social context in which goals are pursued. In the majority of the studies carried out in this area, the effects of different goals are studied in an individual context. Achievement behaviors are thus apprehended most of the time through a pure relationship between an individual and a task. Nevertheless, achievement tasks are usually carried out in contexts including other people with whom one has to deal, interact, and sometimes argue. Notwithstanding, and as noted by Gabriele and Montecinos (2001): "no work has been done on the direct impact of achievement goals in peer-learning situations or has examined the influence of learning and performance goals on social interaction" (p. 155, see also Kaplan, 2004 for a similar discussion). It is thus important to take into account the possibility that these interactions, which occur frequently in classrooms, may moderate the effects of goals on different outcomes including that of learning new academic concepts.

\section{Achievement goals in social interactions}

Although neglected in previous research, the presence of others may be highly relevant in an achievement situation. This is suggested by Utman's meta-analysis (1997), which pointed out that the difference between performance and mastery goals on achievement is greater in studies where participants carry out the task in coaction (with another person working on the same task). Why is the difference between these two goals exacerbated when another person is present? As noted by Dweck and Leggett (1988), when they adopt mastery goal, students are interested in the question: "What is the best way to increase my ability, to achieve mastery?" When they pursue performance goal, on the other hand, students are concerned with the question: "Is my ability adequate or inadequate?" The presence of a coactor in the achievement situation presents the possibility of an answer to both questions. Indeed, the coactor might be both a potential source of information and a social comparison target. The coactor is working on the same problem, and might come up with original explanations, solutions, or answers. These pieces of information can help a student to solve the problem and then master the task. On the other hand, the coactor's responses also give information about his/her ability level and, through social comparison, about the student's own ability.

This is what Butler's results (1992) have suggested. She observed that in a mastery condition, students spent more time on information relevant to learning about a task (the answers given by other students), whereas in an "ability" (i.e., performance) condition, they spent more time on the information that allowed them to calculate an ability score. Duda and Nicholls (1992) also showed that task orientation-but not ego orientation-is linked to the belief that success in the achievement task comes from collaboration with peers. Therefore, it is not surprising that help-seeking behavior (a way to consider peers as a resource) is linked to mastery goal orientation (Karabenick, 2003; Middleton \& Midgley, 1997; Ryan \& Pintrich, 1997). Help seeking also appears more frequently and is more efficient in mastery contexts (Butler \& Neuman, 1995; Ryan, Pintrich, \& Midgley, 2001). In contrast, performance-focused individuals, perceive the other as a threat (Jagacinsky \& Nicholls, 1987; Ryan \& Pintrich, 1997). Therefore, they consider help-seeking behavior as an indication of low ability (Butler \& Neuman, 1995), and avoid this behavior (Karabenick, 2003; Ryan \& Pintrich, 1997).

\section{Social interactions, conflict and learning}

If, as we argue, it is important to study achievement goals in interaction situations, one situation would be particularly meaningful for students carrying out an achievement task: when the coactor disagrees (Buchs, Butera, Mugny, \& Darnon, 2004; Doise \& Mugny, 1984; Johnson \& Johnson, 1993). Indeed, disagreement highlights the possibility that the task has not been mastered (if another solution exists, then the student's proposed solution may be incorrect), and it also questions the student's own competence (perhaps the coactor is more competent; Butera \& Mugny, 1995; Quiamzade \& Mugny, 2001).

It has been argued that the situation of disagreement with other persons is one of high uncertainty (Butera \& Mugny, 2001). Indeed, disagreement introduces doubt about the validity of an answer ("Is my understanding correct?"), thereby producing a "cognitive conflict" (see Berlyne, 1960; Limon, 2001; Piaget, 1975). Moreover, because disagreement stems from social interaction, it also raises uncertainty about personal competence ("Am I more or less competent than the other person on this task?"). Consistently with this idea, McGarty, Turner, Oakes, \& Haslam (1993) have 
demonstrated that disagreement from relevant others enhances subjective uncertainty.

Of particular relevance to the above question is Doise and Mugny's social developmental work (Doise \& Mugny, 1984; Doise, Mugny, \& Pérez, 1998), in which social interaction is seen as a privileged context for progress and learning, because it allows for the confrontation of divergent solutions. Research has shown that when individuals' responses diverge from those of their partner, progress can result. Since this conflict is both social (i.e., the disagreement between two persons) and cognitive (i.e., each individual doubts her/his own answer), the authors labeled it "socio-cognitive conflict" (Mugny, De Paolis, \& Carugati, 1984). A consistent body of evidence has provided empirical support for the beneficial consequences of socio-cognitive conflict on learning and on the quality of reasoning (Ames \& Murray, 1982; Doise \& Mugny, 1984; Doise et al., 1998).

However, the same authors have also noted that sociocognitive conflict does not always lead to progress (Mugny et al., 1984). In fact, two ways of regulating the conflict have been distinguished: Conflict regulation may be either focused on the task and on the understanding of the problem ("epistemic" conflict regulation), or focused on social comparison and on the demonstration of one's own competencies ("relational" conflict regulation, Butera \& Mugny, 2001; Darnon, Muller, Schrager, Pannuzzo, \& Butera, 2006; Mugny et al., 1984). Doise and Mugny (1984) found that reliable progress was observed after a conflictual interaction when conflict was regulated in an epistemic way, whereas no progress was observed when it was regulated in a relational way.

Consistent with this line of research, other authors have shown that the opposition of divergent points of view (i.e., "controversy") can be beneficial and favor learning, but that as soon as learners receive an instruction to win ("debate"), the benefit of disagreement is reduced (Johnson \& Johnson, 1993; Smith, Johnson, \& Johnson, 1981). It is important to note that in this literature, the term "conflict" differs from what has been called "conflict" in the conflict resolution literature (Deutsch, 1973), since (a) it is not always a conflict of interests (but is mainly used to refer to conflict of knowledge), and (b) it does not imply necessarily that the two parties in conflict must reach an agreement (conflict can be regulated by a change in knowledge at the individual level).

\section{Achievement goals and conflict}

Consideration of socio-cognitive conflict and the different styles of conflict regulation may help us address the two unsolved questions in the achievement goal literature discussed earlier. We have pointed out that, although theorists have for a long time considered that mastery goals enhance learning, and that performance goals impair it, the existing literature does not clearly support this claim. To be more precise, it has been shown that mastery goals promote learning only for confusing tasks (Licht \& Dweck, 1984), tasks on which participants are exposed to failures (Covington \& Omelich, 1984), pop exams (considered by authors as a measure of long-term retention, more difficult than mere instrumental learning, Elliot \& McGregor, 1999), and exams in a course described by authors as "academically strenuous" (Grant \& Dweck, 2003, p. 548). This may be why Utman's metaanalysis (1997) found that the advantage of mastery goals (compared to performance goals) is greater when the task is difficult than when it is easy. Likewise, it seems that performance goals impair learning only when the task is difficult (Grant \& Dweck, 2003) or, although this issue is still subject to controversy (cf. Kaplan \& Midgley, 1997), when students perceive their ability as low (Elliott \& Dweck, 1988).

It seems, therefore, that differential effects of mastery and performance goals appear only when uncertainty is high. On the contrary, when students are not uncertain (because the task is easy, or because they have a high competence expectancy on this task), then mastery goals and performance goals should not produce different results. This is where it becomes interesting to take into account the impact of coactors who disagree in studying the effects of achievement goals. Indeed, conflict enhances uncertainty by making individuals doubt their knowledge and competence (e.g. Pérez \& Mugny, 1996).

Hence, in a conflictual learning situation, when a coactor contradicts an individual's knowledge or position, people feel uncertain and might be concerned about reducing this uncertainty (Kagan, 1972), for example by re-assessing the knowledge at hand and engaging in a discussion with the partner. In such a situation, mastery goals should be more beneficial for learning than performance goals, whereas mastery and performance goals should be equivalent in the case of agreement. The present experiment will test this general hypothesis.

\section{Overview and hypotheses}

In the present experiment participants answered some questions about a text to be learned, in a computer-mediated procedure during which the bogus answers of an alleged partner were communicated to them. Achievement goals were operationalized by instructions orienting participants toward mastery, performance or no specific goal (control). The presence or absence of conflict was operationalized by the fictitious partner's position regarding the questions on the text, which was either in disagreement or in agreement with that of the participant. Thus, from now on, we will use the term 
"conflict" at the theoretical level, since this is the term used in the literature discussed above, and the term "disagreement" at the operational level, since it consists of the confrontation of diverging points of view.

We predicted that mastery goals would lead to better learning as compared to performance goals, but only in the case of disagreement. When the partner agrees, there should be no difference in learning across these two goal conditions. What should happen when no specific instruction are introduced? Given the fact that the present experiment is carried out with university students, using academic materials (i.e., in a context where competence is typically defined in terms of normative comparison, cf. Harackiewicz et al., 1998), we expect that the condition with no specific instruction will yield similar results as the performance goals condition. The present study will examine this point.

Finally, in the literature reported above, conflict is seen as a factor that introduces doubts about the validity of knowledge, which is why disagreement is predicted to enhance uncertainty. Thus, we also included supplementary measures designed to assess uncertainty. Disagreement should enhance uncertainty and promote behaviors likely to reduce it: Rereading the text, and engaging in a "discussion" (reply) with the partner.

\section{Method}

\section{Participants}

Seventy-eight French psychology undergraduates, 66 women and 12 men, with a mean age of $22.83(S D=6.3)$ volunteered in this experiment and were randomly assigned to one of the six conditions. In this experiment, as in the pilot study, the majority of participants were women, which reflects the distribution of students in the department of psychology. However, all the effects presented remained significant when controlling for sex.

Procedure and materials

Participants arrived at the laboratory in groups of four. The experiment was presented as a study on computer-mediated cooperative learning. First, they were given the general instructions regarding the task: They would have to study a social psychology text cooperatively in dyads; it was explained that dyads were determined randomly. The text was about eyewitness testimony and had been extracted from an applied social psychology textbook (Py \& Rainis, 2001). This text dealt with theory and experiments that students had never studied before. Participants were also told that they would communicate with the partner in a computer-mediated interaction.

\section{Goal manipulation and pilot study}

Participants were given the specific instructions depending on the conditions. In the mastery condition, instructions were as follows: "It is very important for you to accurately understand the aims of this experiment. You are here to acquire new knowledge that could be useful to you, to understand correctly the experiments and the ideas developed in the text, and to discover new concepts. In other words, you are here to learn." In the performance condition, the instructions were: "It is very important for you to accurately understand the aims of this experiment. You are here to perform, to be good, to get a good grade on the Multiple Choice Test, to prove your abilities, and to show your competencies. Experimenters will evaluate your performance. This evaluation has to be as good as possible." In the last condition, no specific instructions were given.

A pilot study had been previously carried out with 91 French psychology and educational psychology undergraduates (10 men and 75 women, six did not report their sex), with a mean age of 22.38 ( $S D=5.68)$, to test that our experimental manipulation was effective in inducing different achievement goals. In this study the performance vs. the mastery instructions vs. no instructions were given to participants who then had to read a text, and to answer a goal questionnaire. This questionnaire contained six items from Elliot and McGregor's (2001) scale (three items for the mastery-approach goal and three for the performanceapproach goal. See Darnon and Butera, 2005, for validation in French) adapted to the experimental situation (i.e., "class" was replaced by "experiment").

Results indicated that, as far as mastery goals are concerned, the contrast opposing the mastery condition to the other two was significant, $F(1,88)=5.91, p<.02, \eta^{2}=.06$, whereas the orthogonal contrast (opposing performance to the "no instruction" condition) was not, $F(1,88)=1.44$, $p=.23, \eta^{2}=.02$. The mastery instructions $(M=5.1$, $S D=1.3)$ led to a greater adoption of mastery goals than the performance instructions $(M=4.61, S D=1.08)$ and the "no instruction" condition $(M=4.23, S D=1.37)$. As far as performance goals are concerned, the contrast opposing the performance condition to the other two was significant, $F(1,88)=6.93, p<.009, \eta^{2}=.07$, whereas the orthogonal contrast (opposing mastery to the "no instruction" condition) was not, $F(1,88)<1$. The performance instructions $(M=3.33, S D=1.54)$ increased the adoption of performance goals, as compared to the mastery instructions $(M=2.49, S D=1.5)$ and the "no instruction" condition $(M=2.53, S D=1.09)$. The results of this pilot study revealed that our manipulation affected students' responses on a goal orientation questionnaire. As a consequence, these instructions were used to induce goals in the main 
experiment. It is worth noting that, although it was merely a pilot study, this experiment has a more general value: Our results showed that goal manipulations can lead to a real modification in goal orientation, a point that so far has yielded inconsistent results in the achievement goals literature.

\section{Task}

Since the interaction was not face-to-face, and in order to maximize the chances that the participants would consider the computer-mediated communication as relevant and important, participants were informed of the importance of the complementarity of points of view and the advantages of taking into account the other's point of view (see Butera, Huguet, Mugny, \& Pérez, 1994, for more details on the task used for this demonstration).

The participants were then seated in different rooms in front of the computers. Separately, they were each told that they would be first to answer the questions about the text. The text was divided into four sections. For each section, one question was asked. At the beginning, the first part of the text appeared on the screen. When they had finished reading, participants pressed a button and the question appeared on the screen. They had a space to write down their answer. They then sent their answer to "their partner" (who in fact did not receive it). After waiting for a few seconds, they received the so-called "partner's answer," which in fact was an automatic pre-recorded sentence.

\section{Disagreement manipulation}

The messages had been standardized in order to induce disagreement or not, which was the second independent variable. It was supposed that the participants would give the correct answer, which was always the case. The "partner's" answer (actually the pre-recorded answer) was either in disagreement or in agreement with the participant's. For example, the question "What are the effects of the presence of a weapon on the recall of a criminal event?" was correctly answered by participants by reporting that "It lowers the recall." In the disagreement condition, the partner's answer was: "I rather thought that the presence of a weapon enhances attentional focus and then the witness is more attentive, and remembers better the elements of the situation." In the agreement condition, the partner's answer was "Yes, I think that's it, the presence of a weapon lowers the recall." Disagreements were therefore based on incorrect answers, but corresponded to a plausible (non aberrant) point of view.

After receiving this answer, participants could either decide to again send an answer to their partner or to continue, in which case the rest of the text appeared on the screen. They also had the opportunity to go back to the text if they wished. The same procedure was repeated for the four questions. To strengthen the credibility of the experimental manipulation, there were three disagreements and one agreement in the disagreement conditions, and four agreements in agreement conditions. After this "interaction" phase, participants answered a questionnaire (see next section) and completed a multiple-choice test of learning. Finally, in a delayed posttest, carried out 1 to 2 weeks later, participants were asked to complete the same multiple-choice test again. They were then thoroughly debriefed and thanked.

\section{Dependent measures}

For all items, participants were asked to answer on a scale ranging from 1 (very little) to 7 (very much).

\section{Manipulation check}

Participants were asked to report the perceived quantity of divergence between their partner and themselves.

\section{Uncertainty}

Participants were asked to report the extent to which their partner's answer made them think they "had not understood the text well," "weren't very competent in these types of tasks," and made them "feel afraid to say or to have said something wrong." They were also asked to report how much they thought they "had a good understanding of the text," "were able to answer the questions," "were competent in these types of tasks." These six items were aggregated for a measure of uncertainty, after reverse-coding the latter three $(\alpha=.76, M=2.53, S D=.96)$.

\section{Return to the text}

Participants had the opportunity to go back to the text after the partner's answer, as many times as they wanted. The number of returns was recorded $(M=1.01, S D=1.29)$.

\section{Reply to the partner}

After the partner's answer, participants also had the opportunity to reply to their partner. The number of replies was recorded. The possible range was from 0 (never answered) to 4 (answered for all questions, $M=1.72, S D=1.30$ ).

\section{Learning}

The main dependent variable was learning, measured by the grade obtained on the multiple-choice test (MCT). This MCT contained 12 questions assessing the understanding of the text. It is important to note that the questions about the text asked during the "social interaction" were fairly easy, as 
we needed participants to answer correctly all the questions. Accordingly, this part of the task might have been seen as fairly easy, and not very challenging. However, the MCT assessing the understanding of the text was quite difficult. Indeed, these questions did not measure the mere recognition of the content of the text, but the full understanding of the concepts, the ability to apply them to specific situations (e.g., "Imagine you are an actor and one of your dreams is that people will recognize you when they see you in the street. Which one of the following scenes could satisfy your wish?"). Several authors have argued that the ability to transfer knowledge and apply it to a new situation is a sign of learning (e.g., Doise, Mugny, \& Perret-Clermont, 1975).

Performance on this test was measured twice: first, just after the interaction and second, 1-2 weeks later. Due to negative points for mistakes $(-0.25)$, this measure ranged from -3 to $+12(M=7.29, S D=2.20)$.

\section{Results}

Reaction to conflict and uncertainty

\section{Manipulation check}

Participants in the agreement condition never perceived any disagreement (they all circled " 1 ") whereas all of the 39 participants in the disagreement condition ticked within the 2 and 7 range (that is, at least "a little" perceived disagreement), $\chi^{2}(1)=82.09, p<.001$.

A 3 (goal: mastery, performance, no instruction) * 2 (partner's position: disagreement, agreement) ANOVA was performed on each of the following measures.

\section{Uncertainty}

The main effect of the partner's position, $F(1,71)=67.49$, $p<.001, \eta^{2}=.49$, indicated that disagreement $(M=3.20$, $S D=.86$ ) induced a higher uncertainty than agreement
$(M=1.87, S D=.49)$. Neither the main effect of goals nor the interaction reached significance.

\section{Return to the text}

A main effect of the partner's position was observed, $F(1$, $72)=28.12, p<.001, \eta^{2}=.28$. Participants chose to go back to the text more often after disagreement $(M=1.66$, $S D=1.46)$ than after agreement $(M=.33, S D=.58)$. Neither the main effect of goals nor the interaction reached significance.

\section{Reply to the partner}

A main effect of partner's position was observed on the number of replies to the partner, $F(1,72)=97.08, p<.001$, $\eta^{2}=.57$. After disagreement, participants replied more often $(M=2.69, S D=.83)$ than after agreement $(M=.74$, $S D=.88)$. Neither the main effect of goals nor the interaction reached significance.

\section{Learning}

Neither the main effect of goals, $F(1,72)<1$, nor that of the partner's position $F(1,72)<1$, was observed on the score obtained on the MCT submitted just after the interaction. Nevertheless, as expected, the interaction between the two variables was significant, $F(2,72)=3.45, p<.04, \eta^{2}=.09$. The same interaction was observed for the delayed learning score (obtained on the same MCT after a delay of 1-2 weeks), $F(2,72)=3.35, p<.05, \eta^{2}=.09$. Since they follow the same pattern and are highly correlated $(r=.58, p<.001)$, the two scores (immediate and delayed) were aggregated in a single measure of learning.

The same analyses were then repeated on this general score of performance. Neither the main effect of conflict, $F(1,72)=1.33, p=.25$, nor the main effect of goals, $F(2,72)=1.61, p=.21$ were significant, but the interaction was, $F(2,72)=4.32, p<.02, \eta^{2}=.11$. Results are presented in Fig. 1. Simple effects showed that, as predicted,
Fig. 1 Mean learning (immediate and delayed MCT score) as a function of partner's position and goal

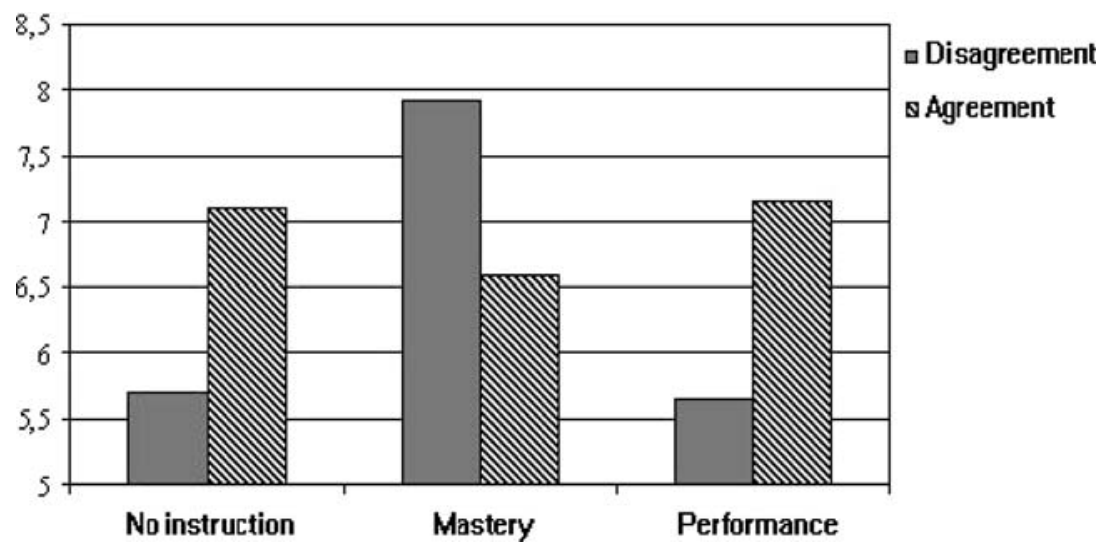


when there was disagreement, the mastery goal condition $(M=7.93, S D=2.05)$ led to better learning than the performance goal condition, $M=5.66, S D=1.56, F(1,72)=8.55$, $p<.005, \eta^{2}=.11$, and the "no instruction" condition, $M=5.7, S D=1.54, F(1,72)=8.27, p<.006, \eta^{2}=.10$. The two latter conditions did not differ from each other, $F(1,72)$ $<1$. In the case of agreement, the three groups were equivalent $(M=6.59, S D=1.53$ for mastery goals, $M=7.15$, $S D=2.9$ for performance goals, and $M=7.11, S D=1.92$ for the "no instruction" condition, all $F \mathrm{~s}<1$ ).

It is worth noting, as an additional finding, that simple effects also indicated that in the mastery goal conditions, disagreement tended to lead to a better learning than agreement, $F(1,72)=3.01, p<.09, \eta^{2}=.04$. The reverse was observed in the performance goal condition where disagreement tended to lead to a lower level of learning than agreement, $F(1,72)=3.69, p<.06, \eta^{2}=.05$. The same trend was observed in the "no instruction" condition, $F(1,72)=3.27$, $p<.08, \eta^{2}=.04$.

\section{Discussion}

The aim of the present research was to explore the possible cross-fertilization of two theoretical frameworks, namely achievement goal theory (e.g., Dweck, 1986) and sociocognitive conflict theory (e.g., Doise \& Mugny, 1984). Our synthesis of these two bodies of literature suggests that interaction with others in the context of an academic task can be an important moderator of achievement goal effects. Indeed, the present results indicate that when the partner disagreed, the induction of mastery goals led to significantly better learning than did the induction of performance goals and the "no instruction" condition. This was not the case in the agreement conditions, where inducing mastery goals did not influence learning relative to the two other conditions. These results appear to be rather robust, since they apply to both the immediate measure of learning and the delayed measure, taken one to two weeks later. Thus, our hypothesis was fully supported by the present data.

It is important to consider the processes through which mastery goals induced better learning outcomes than performance goals, specifically in case of conflict. We argued that conflict produces uncertainty and our results clearly showed that a disagreeing partner enhanced perceived uncertainty, and encouraged activities likely to reduce this uncertainty such as returning to the text and replying to the partner. This point is quite important if one considers that early work on social comparison (Festinger, 1954) showed that it is precisely when uncertainty is high that people feel the need to compare to others (Schachter, 1959). Conflict should therefore motivate people to compare themselves to others and try to regulate this conflict. As mentioned earlier, literature on socio-cognitive conflict has argued that conflict can be regulated in two rather different ways, either in an epistemic or a relational way (Doise \& Mugny, 1984; Quiamzade \& Mugny, 2001). Epistemic conflict regulation corresponds to the attempt to understand each point of view and to reexamine the material for a better understanding; in contrast, relational conflict regulation aims at proving that one is right while the other is wrong. Interestingly, a recent study demonstrated that participants' goals predicted different modes of conflict regulation in conflictual situations (Darnon et al., 2006). Mastery goals predicted epistemic conflict regulation whereas performance goals predicted relational conflict regulation. Thus, it seems reasonable to think that in the present study, although uncertainty was high in all conflict conditions, attempts to reduce uncertainty (returning to the text, discussing with the partner) might not have served the same function in the two goal conditions (cf. Butler, 1995). More specifically, conflict regulation might have been aimed at checking understanding in the mastery condition (epistemic conflict regulation) but at proving that one is right and the other person is wrong in the performance condition (relational conflict regulation). This could explain why conflict produces better learning under mastery than under performance goals. This would also be consistent with the idea that under mastery goals the other person is perceived as a help, or as a support for understanding and learning, whereas under performance goals the other person is perceived as a target for social comparison (Butler, 1992).

Moreover, the present results represent an important contribution to the achievement goal literature. Indeed, to explain inconsistencies in the different effects of mastery and performance goals, Harackiewicz et al. (1998) suggested that "we might expect to see positive effects of mastery goals in (...) classes where coursework is more likely to require deep processing, thoughtful integration of materials, and sustained effort and involvement" (p. 17). As noted earlier, literature has shown that mastery goals only allow for enhanced learning when the task requires thorough attention and deep examination of its content (as in Elliot \& McGregor 1999; Grant \& Dweck, 2003). In these types of tasks, individuals are uncertain, and in order to solve the task they must examine the content of the task more deeply. These activities are favored by mastery goals (e.g., Nolen, 1988). Although many factors can account for the induction of uncertainty, we think that our interpersonal manipulation of socio-cognitive conflict was particular effective in producing uncertainty. Indeed, disagreement raised participants' levels of doubt and possibly rendered the task more challenging. In this situation, mastery goals enhanced learning. Conversely, when the partner agreed, the participant's knowledge was not put into question, and mastery goals were not more effective in helping the participant accomplish the task. 
Our results also highlight important issues about the effects of social interaction on learning. More specifically, many authors have argued that socio-cognitive conflict is a key element that makes social interactions between peers beneficial for learning (Doise \& Mugny, 1984; Mugny et al., 1984). However, the same researchers have pointed out that some situations may prevent this kind of conflict from having positive consequences. This seems most likely to occur in situations in which the competence of one participant represents a threat for the competence of the other (Butera \& Mugny, 2001; Quiamzade \& Mugny, 2001). For example, in a study by Butera and Mugny (1995) using an inductive reasoning task, participants were led to disagree with a fictitious partner, and had to compare to this partner either in a competitive or in a non-competitive manner. Results revealed a negative correlation between the participants' perceived competence and that of the partner, as well as biased hypothesis testing in the reasoning task, in the competitive condition; conversely, results revealed a positive correlation between the participants' perceived competence and that of the partner, as well as diagnostic hypothesis testing in the reasoning task in the non-competitive condition. The present study indicates that goals can create such contexts in which confrontation of points of views can have either positive or negative effects. Indeed, simple effects, although only marginal, suggest that only mastery goals created a context in which conflict led to positive effects in terms of learning. These results could explain why in some contexts, where performance goals are too salient, conflict does not enhance learning.

It is worth noting, however, that while most authors agree that epistemic conflict regulation has beneficial consequences, there is more disagreement about the effects of relational conflict regulation. For some social developmental psychologists, relational conflict regulation in peer learning only cancels the benefits of conflict (Mugny et al., 1984). Other results, however, suggest that it can have detrimental effects on task resolution (Darnon, Buchs, \& Butera, 2002). In the latter research, two different kinds of conflict were introduced during peer learning. In a "relational conflict" condition, disagreement was presented in a way that threatened participants' competence (e.g., "you have not understood correctly, let me explain to you ..."). In an "epistemic conflict" condition, it was presented in a non-threatening way (e.g., "I would rather say that ..."). This experiment indicated that the relational conflict led to poorer learning than the epistemic conflict. Moreover, this type of conflict undermined learning relative to a control group where no conflict was introduced (see Monteil \& Chambres, 1990 for a similar result). The results of the present study contribute to this debate by giving support to this latter view: When associated with performance goals, conflict tended to be detrimental for learning.
Finally, it should be noted that results in the condition where no specific instructions were given are quite close to the results of the performance goal condition. This similarity supports Harackiewicz et al.'s (1998) point of view that the dominant norm in a university context is one of normative comparisons. Bearing this in mind, it seems likely that our performance goal instruction has simply enhanced the social comparison stakes already present in all educational structures (Levine, 1983).

Some limitations may be noted. Notably, the way the instructions were phrased in these studies suggests that the performance goals induced in the present research are in fact performance-approach goals (Elliot, 1997; Elliot \& Harackiewicz, 1996). It is possible, however, that conflict has oriented the general performance goals toward performanceavoidance goals by enhancing uncertainty and perhaps even fear of failure; this would be consistent with the detrimental effect of conflict in the performance condition. This interpretation could be examined in future research by asking participants to report their goals after disagreements or agreements. It could also be examined by comparing manipulated performance-approach and performance-avoidance goals. Future research will have to examine this point. Another limitation stands in the fact that the main dependent variable examined in the present study, namely learning, is not a "social" variable per se. An interesting direction for future research would be to examine the nature of the social interactions that follow socio-cognitive conflict in different goals conditions, as for example in Darnon, Doll and Butera (in press), in order to examine the way students further interact with each other.

Despite these limitations, this research has shown that mastery goals do favor learning over performance goals in an interactive activity, but - and this is the specific contribution of the present paper-as long as the two partners present contradictory points of views. As an extension, these results emphasize the importance for teachers using conflict in the classroom to take into account the context of its occurrence. Encouraging students to interact about conflictual issues in a context in which mastery goals are emphasized can be beneficial for learning. Nevertheless, it is important that teachers using conflict avoid performance issues (e.g., normative comparisons) and enhance epistemic issues (e.g., the construction of knowledge; Maehr \& Midgley, 1991), in order to allow their students to benefit from this confrontation.

Acknowledgements This work was supported by an "Ecole et Sciences Cognitives" fund granted by the French Ministry for Research, and by the Swiss National Science Foundation. We wish to express our gratitude to Dominique Muller and Caroline Pulfrey for their comments on previous versions of this article. 


\section{References}

Ames, G. J., \& Murray, F. B. (1982). When two wrongs make a right: Promoting cognitive change by social conflict. Developmental Psychology, 18, 894-897.

Berlyne, D. E. (1960). Conflict, arousal, and curiosity. New York: McGraw-Hill.

Buchs, C., Butera, F., Mugny, G., \& Darnon, C. (2004). Conflict elaboration and cognitive outcomes. Theory into Practice, 43, 23-31.

Butera, F., Huguet, P., Mugny, G., \& Pérez, J. A. (1994). Socioepistemic conflict and constructivism. Swiss Journal of Psychology, 53, 229-239.

Butera, F., \& Mugny, G. (1995). Conflict between incompetences and influence of a low expertise source in hypothesis testing. European Journal of Social Psychology, 25, 457-462.

Butera, F., \& Mugny, G. (2001). Conflicts and social influences in hypothesis testing. In C. K. W. De Dreu \& N. K. De Vries (Eds.), Group consensus and minority influence. Implications for innovation (pp. 161-182). Blackwell.

Butler, R. (1992). What young people want to know when: Effects of mastery and ability goals on interest in different kinds of social comparisons. Journal of Personality and Social Psychology, 62, 934-943.

Butler, R. (1995). Motivational and informational functions and consequences of children's attention to peers' work. Journal of Educational psychology, 87, 347-360.

Butler, R., \& Neuman, O. (1995). Effects of task and ego achievement goals on help-seeking behaviors and attitudes. Journal of Educational Psychology, 87, 261-271.

Covington, M. V., \& Omelich, C. L. (1984). Task-oriented versus competitive learning structures: Motivational and performance consequences. Journal of Educational Psychology, 76, 10381050.

Darnon, C., Buchs, C., \& Butera, F. (2002). Epistemic and relational conflict in sharing information during cooperative learning. Swiss Journal of Psychology, 61, 139-151.

Darnon, C., \& Butera, F. (2005). Buts d'accomplissement, stratégies d'étude, et motivation intrinsèque: présentation d'un domaine de recherche et validation française de l'échelle d'Elliot et McGregor (2001) [Achievement goals, study strategies, and intrinsic motivation: Presenting a domain of research and the French validation of Elliot and McGregor's scale (2001)]. L'Année Psychologique, $105,105-131$.

Darnon, C., Doll, S., \& Butera, F. (in press). Dealing with a disagreeing partner: Relational and epistemic conflict elaboration. European Journal of Psychology of Education.

Darnon, C., Muller, D., Schrager, S. M., Pannuzzo, N., \& Butera, F. (2006). Mastery and performance goals predict epistemic and relational conflict regulation. Journal of Educational Psychology, 98, 766-776.

Deutsch, M. (1973). The resolution of conflict. Constructive and destructive processes. New Haven and London: Yale University Press.

Doise, W., \& Mugny, G. (1984). The social development of the intellect. Oxford: Pergamon Press.

Doise, W., Mugny G., \& Pérez, J. A. (1998). The social construction of knowledge: Social marking and socio-cognitive conflict. In U. Flick (Ed.), The psychology of the social (pp. 77-90). Cambridge: Cambridge University Press.

Doise, W., Mugny, G., \& Perret-Clermont, A. N. (1975). Social Interaction and the development of cognitive operations. European Journal of Social Psychology, 5, 367-383.

Duda, J. L., \& Nicholls, J. G. (1992). Dimensions of achievement motivation in schoolwork and sport. Journal of Educational Psychology, 84, 290-299.
Dweck, C. S. (1986). Motivational processes affecting learning. American Psychologist, 41, 1040-1048.

Elliot, A. J. (1997). Integrating the "classic" and "contemporary" approaches to achievement motivation: A hierarchical model of approach and avoidance motivation. In M. Maehr \& P. Pintrich (Eds.), Advances in motivation and achievement (Vol. 10, pp. 143-179). Greenwich, CT: JAI.

Elliot, A. J., \& McGregor, H. A. (1999). Test anxiety and the hierarchical model of approach and avoidance achievement motivation. Journal of Personality and Social Psychology, 76, 628-644.

Elliot A. J., \& McGregor, H. A. (2001). A $2 * 2$ Achievement Goal Framework. Journal of Personality and Social Psychology, 80, 501-519

Elliott, E. S., \& Dweck, C. S. (1988). Goals: An approach to motivation and achievement. Journal of Personality and Social Psychology, 54, 5-12.

Festinger, L. (1954). A theory of social comparison processes. Human Relations, 7, 117-140.

Gabriele, A. J., \& Montecinos, C. (2001). Collaborating with a skilled peer: The influence of achievement goals and perception of partners' competence on the participation and learning of low-achieving students. The Journal of Experimental Education, 69, 152-176.

Grant, H., \& Dweck, C. (2003). Clarifying achievement goals and their impact. Journal of Personality and Social Psychology, 85, 541-553.

Harackiewicz, J. M., Barron, K., Carter, S. M., Lehto, A. T., \& Elliot, A. J. (1997). Predictors and consequences of achievement goals in the college classroom: Maintaining interest and making the grade. Journal of Personality and Social Psychology, 73, 1284-1295.

Harackiewicz, J. M., Barron, K., \& Elliot, A. J. (1998). Rethinking achievement goals: When are they adaptive for college students and why? Educational Psychologist, 33, 1-21.

Harackiewicz, J. M., Barron, K., Pintrich, P. R., Elliot, A. J., \& Thrash, T. M. (2002). Revision of achievement goal theory: Necessary and illuminating. Journal of Educational Psychology, 94, 638-645.

Jagacinsky, C. M., \& Nicholls, J. G. (1987). Competence and affect in task involvement and ego-involvement. The impact of social comparison information. Journal of Educational Psychology, 79, $107-114$

Johnson, D. W., \& Johnson, R. T. (1993). Structuring academic controversy. In S. Sharan (Ed.), Handbook of cooperative learning methods. Westport: Greenwood Publishing group.

Kagan, J. (1972). Motives and development. Journal of Personality and Social Psychology, 22, 51-66.

Kaplan, A. (2004). Achievement goals and intergroup relations. In P. R. Pintrich \& M. L. Maehr (Eds.), Advances in research on motivation and achievement: Vol. 13: Motivating students, improving schools: The legacy of Carol Midgley (pp. 97-136). United Kingdom: Elsevier.

Kaplan, A., \& Midgley, C. (1997). The effect of achievement goals: Does level of perceived academic competence make a difference? Contemporary Educational Psychology, 22, 415-435.

Karabenick, S. A. (2003). Seeking help in large college classes: A person-centered approach. Contemporary Educational Psychology, 28, 37-58.

Levine, J. M. (1983). Social comparison and education. In J. M. Levine \& M. C. Wang (Eds.) Teacher and student perception: Implications for learning (pp. 29-55). Hillsdale, NJ.: Lawrence Erlbaum Associates

Licht, B. G., \& Dweck, C. S. (1984). Determinants of academic achievement: The interaction of children's achievement orientations with skill area. Developmental Psychology, 20, 628-636.

Limon, M. (2001). On the cognitive conflict as an instructional strategy for conceptual change: A critical appraisal. Learning and Instruction, 11, 357-380. 
Maehr, M. L., \& Midgley, C. (1991). Enhancing students' motivation: a schoolwide approach. Educational Psychologist, 26, 399-427.

Middleton, M., \& Midgley, C. (1997). Avoiding the demonstration of lack of ability: An underexplored aspect of goal theory. Journal of Educational Psychology, 89, 710-718.

Midgley, C., Kaplan, A., \& Middleton, M. (2001). Performanceapproach goals: good for what, for whom, under what circumstances, and at what cost? Journal of Educational Psychology, $93,77-86$.

McGarty, C., Turner, J. C., Oakes, P. J., \& Haslam, S. A. (1993). The creation of uncertainty in the influence process: The roles of stimulus information and disagreement with similar others. European Journal of Social Psychology, 23, 17-38.

Monteil, J. M., \& Chambres, P. (1990). Eléments pour une exploration des dimensions du conflit socio-cognitif: une expérimentation chez l'adulte [Elements for exploring dimensions of sociocognitive conflict: an experiment on adults]. Revue Internationale de Psychologie Sociale, 4, 499-517.

Mugny, G., De Paolis, P., \& Carugati, F. (1984). Social regulations in cognitive development. In W. Doise \& A. Palmonari (Eds.), Social interaction in individual development (pp. 127-146). Cambridge: Cambridge University Press.

Nicholls, J. G. (1984). Achievement motivation: Conceptions of ability, subjective experience, task choice, and performance. Psychological Review, 91, 328-346.

Nolen, S. B. (1988). Reasons for studying: Motivational orientations and study strategies. Cognition and Instruction, 5, 269-287.
Piaget, J. (1975). L'équilibration des structures cognitives [The equilibration of cognitive structures]. Paris : Presses Universitaires de France.

Pérez, J. A., \& Mugny, G. (1996). The conflict elaboration theory of social influence. In E. Witte, H., \& J. Davis, H. (Eds.), Understanding Group Behavior (Vol. 2, Small Group Processes and Interpersonal Relations, pp. 191-210). New Jersey: Lawrence Erlbaum Associates.

Py, J., \& Rainis, N. (2001). System variables and estimator variables in eyewitness testimony. In F. Butera \& G. Mugny. (Eds.), Social influence in social reality. Promoting individual and social change (pp. 249-264). Ashland, US: Hogrefe \& Huber Publishers.

Quiamzade, A., \& Mugny, G. (2001). Social influence dynamics in aptitude tasks. Social Psychology of Education, 4, 311-334.

Ryan, A. M., \& Pintrich, P. R. (1997). Should I ask for help? The role of motivation and attitudes in adolescents' help seeking in math class. Journal of Educational Psychology, 89, 329-341.

Ryan, A. M., Pintrich, P. R., \& Midgley, C. (2001). Avoiding seeking help in the classroom: Who and why? Educational Psychology Review, 13, 93-114.

Schachter, S. (1959). The psychology of affiliation. London: Tavistock.

Smith, K., Johnson, D. W., \& Johnson, R. T. (1981). Can conflict be constructive? Controversy versus concurrence seeking in learning groups. Journal of Educational Psychology, 73, 651-663.

Utman, C. H. (1997). Performance effects of motivational state: A metaanalysis. Personality and Social Psychology Review, 1, 170-182. 